\title{
EL VINCULO MIGRACIÓN Y DESARROLLO EN EL MARCO DE LA POLITICA PÚBLICA ESPAÑOLA
}

ANNA SANMARTÍN ORTÍ

RESUMEN: Las múltiples relaciones que pueden generarse entre la migración y el desarrollo aparecen como una cuestión no resuelta en la literatura. El que las migraciones puedan favorecer e impulsar el desarrollo de las regiones entre las que se producen, depende en gran medida del contexto que se analice y de la gestión política de los gobiernos. Por ello, a partir del análisis de la documentación y el discurso procedente de las administraciones públicas, en este artículo se aborda el caso específico español. Revisamos los elementos contextuales y las concepciones sobre la inmigración que confluyen en una apuesta política por establecer mecanismos de intervención que favorezcan y potencien esta relación. Entre ellos, el enfoque del codesarrollo, una propuesta específicamente europea y, en la actualidad, recogida e implementada por los actores que en España trabajan en los ámbitos de la cooperación y las migraciones.

PALABRAS CLAVE: migración, desarrollo, codesarrollo, políticas, España.

ABSTRACT: The multiple interactions between migration and development have not been sufficiently explored in the current literature. The idea that migration can foster and encourage development in the regions that produce it greatly depends on the context and the political approach of the governments in question. This article examines the case of Spain through an analysis of public management documents and discourse, as well as the ways in which contextual elements and concepts of immigration come together in a political attempt to establish intervention mechanisms that can assist and encourage a beneficial relationship. Among them is the specifically European approach of co-development, which is currently implemented in Spain by actors in the fields of cooperation and migration.

KEYWORDS: migration, development, co-development, policy, Spain.

\footnotetext{
* Investigadora, Miembro del Grupo de Estudios sobre Migraciones Internacionales (GEMI) de la UCM.

Instituto Universitario de Investigación Ortega y Gasset. Universidad Complutense de Madrid (UCM)

e-mail: anna-sanmartin@hotmail.com
} 


\section{INTRODUCCIÓN ${ }^{1}$}

U no de los debates abiertos en el campo de los estudios migratorios y de cooperación, es aquel que se refiere a las múltiples conexiones y posibilidades para relacionar las migraciones con el desarrollo, las maneras en las que los procesos y grados de desarrollo afectan a las migraciones y viceversa, al sentido de dicha influencia mutua y los elementos que condicionan de manera preponderante esta relación.

Los factores que provocan los movimientos de las personas y que conforman el desarrollo han sido tratados ampliamente en la literatura de forma independiente, y en la actualidad asistimos precisamente a un interés creciente por analizar de qué modo se afectan entre sí y qué canales de intervención son los idóneos para potenciar esa relación: las ventajas e inconvenientes de impulsar el nexo, sus potencialidades, el modo de organizar los esfuerzos, los recursos necesarios, los protagonistas en la gestión de los mismos, y un largo etc. Se trata de una cuestión no resuelta en la literatura (Appleyard, 1992); las respuestas no son unívocas, no son las mismas para todos los casos, y las conclusiones de los estudios varían dependiendo de las variables que se consideren y del punto de vista que se adopte.

La unión del migrar con el desarrollo no es algo nuevo, ha estado muy presente en las motivaciones de los emigrantes que fueron a hacer las Américas, o que migraron del campo a la ciudad, y que apostaron por la migración como una vía para mejorar su situación y la de los suyos. La movilidad humana, por consiguiente, ha sido siempre parte intrínseca del desarrollo humano y juega un papel central en los procesos globales y locales de cambio social, económico y político: es a la vez moldeado por ellos y contribuye a dar forma a esas transformaciones sociales (Hass et al, 2009). Sin embargo, hoy se entiende el vínculo en unos parámetros determinados y el impulso de dicho nexo, como una meta a alcanzar. Los esfuerzos políticos, sociales y económicos en este sentido, se dirigen hacia la lucha contra la pobreza y las desigualdades en un mundo interconectado, terreno en que las migraciones internacionales, a través de una gestión determinada, se considera pueden tener un papel relevante.

Asistimos pues a un interés creciente por la incidencia de las migraciones, en diferentes grados y maneras, en el desarrollo de las regiones donde se producen. Las migraciones actuales tienen lugar en el marco de la globalización y afectan a las relaciones entre el norte y el sur en ámbitos tan diversos como el comercio internacional, las inversiones, la gestión de la deuda externa, o la firma de acuer-

\footnotetext{
1 Este artículo es un avance de parte de la tesis doctoral de la autora: «El codesarrollo en España: un análisis de la implicación de los migrantes», un trabajo de investigación de cuatro años en el marco de los contratos de Personal Investigador en Formación de la Universidad Complutense de Madrid (UCM).
} 
dos políticos entre países y regiones conectados por los flujos. Todo ello implica una serie de cambios profundos, ya que pone en cuestión los límites de la gestión nacional de los nuevos procesos e introduce nuevas lógicas a considerar para entender y aprehender la realidad. Un marco específico en el que los analistas sitúan sus estudios, los actores de la sociedad civil despliegan sus iniciativas y los gobiernos enmarcan sus políticas públicas.

Existe una importante producción científica que analiza la relación migración y desarrollo basándose en el caso del sistema migratorio conformado entre México y Estados Unidos (Delgado, Márquez y Rodríguez (2009), Portes, Escobar y Walton (2006), o García Zamora (2005), entre otros. Para el caso español, los trabajos son menos numerosos y más recientes. Por ello, en este artículo nos interesa profundizar en las particularidades que caracterizan el enfoque y las acciones impulsadas desde España, y nos aproximaremos a ello atendiendo al discurso y a la documentación política. Se trata de entender las razones que convierten el nexo migración y desarrollo en una clara apuesta política nacional, así como los dispositivos a partir de los cuales se trata de operacionalizar dicha relación.

\section{CONTEXTUALIZACIÓN: LA INCORPORACIÓN DEL NEXO MIGRACIÓN Y DESARROLLO EN EL ACERVO INTERNACIONAL}

Entre la documentación internacional más reciente encontramos múltiples alusiones al vínculo migración y desarrollo, a la interdependencia de ambos fenómenos en un sentido positivo. En la Declaración del Milenio (2000) y en la Conferencia de Monterrey sobre la financiación del desarrollo (2002) no se mencionaba todavía el posible impacto de las migraciones en los procesos de desarrollo. Pero en 2003 la Organización Internacional para las Migraciones de Naciones Unidas (OIM) ya señala cómo:

[...] los vínculos entre migración y desarrollo son muchos y complejos. No son nuevos, pero el enfoque del debate internacional ha evolucionado con los años. En el pasado, la tendencia consistía en centrarse en las implicaciones negativas de la migración en relación con el desarrollo [...] No obstante, la comunidad internacional ha ido centrándose, cada vez más, en los vínculos positivos. Así pues, en general se reconoce que, si se gestiona correctamente, la migración internacional puede resultar beneficiosa para el desarrollo local (OIM, 2003: 2).

Esta afirmación muestra la línea del debate internacional y apunta hacia una determinada comprensión y definición de los fenómenos, que los gestores y hacedores de políticas públicas traducirán en elementos normativos e instrumentos de intervención concretos para actuar sobre ellos. Contamos con sucesivas resoluciones de la Asamblea General de las Naciones Unidas dentro de este marco 
sobre migraciones y desarrollo, ${ }^{2}$ que establecen las bases para la celebración en septiembre de 2006 del Diálogo de Alto Nivel, dedicado a la migración internacional y el desarrollo. Y el último Informe sobre Desarrollo Humano del PNUD -Superando barreras: movilidad y desarrollo humanos (PNUD, 2009)- aborda precisamente esta cuestión.

Por su parte la Unión Europea, en las recomendaciones derivadas de la Cumbre de Tampere (1999), apunta la necesidad de establecer una política global y común en materia migratoria para la Unión, e incorpora la cooperación al desarrollo como un instrumento básico de gestión en el ámbito internacional. Así, en el apartado dedicado al asilo y la inmigración, recoge:

La Unión Europea necesita un enfoque global de la inmigración que trate los problemas políticos, de derechos humanos y de desarrollo de los países y regiones de origen y tránsito. Para ello es necesario luchar contra la pobreza, mejorar las condiciones de vida y las posibilidades de trabajo, prevenir los conflictos, consolidar los Estados democráticos y garantizar el respeto de los derechos humanos, en particular los derechos de las minorías.

Y para ello invita a la coherencia en las políticas interiores y exteriores de la Unión e introduce un concepto -el codesarrollo- que cobrará relevancia entre las propuestas europeas:

Otro elemento clave para lograr el éxito de esta política será la colaboración con terceros países interesados, con objeto de fomentar el codesarrollo (Punto I, 11).

Desde entonces, Europa ha elaborado diversos documentos que continúan en esta línea y en los que la relación entre el desarrollo y las migraciones se está trabajando insistentemente. Entre ellos, nos interesa destacar el publicado en diciembre de 2005, siguiendo una iniciativa impulsada por España: «Planteamiento global sobre migración: Acciones prioritarias en África y el Mediterráneo», que adoptó el Consejo Europeo y que se ocupó de un amplio abanico de cuestiones ligadas a la migración (relaciones exteriores, desarrollo y empleo, justicia, libertad y seguridad).

El establecimiento de un programa de trabajo con África no puede ser entendido sin recordar los acontecimientos dramáticos que protagonizó la migración subsahariana y marroquí hacia el continente en 2005, y que confluyó en la iniciativa hispano-marroquí de la Conferencia ministerial euroafricana sobre las migraciones y el desarrollo en julio de 2006. En ella se reunieron unos 60 países ubicados a lo largo de las rutas migratorias de África central y occidental para debatir un

\footnotetext{
2 Resolución de 2004 Migración Internacional y desarrollo, Asamblea General 58/208; resolución de 2005 Migración Internacional y desarrollo, Asamblea General 59/241; resolución de 2006 Migración internacional y desarrollo, Asamblea General 60/227.
} 
Plan de Acción elaborado por España, Francia y Marruecos. El Plan incluyó temas concernientes a las políticas de inmigración, los acuerdos bilaterales y multilaterales sobre controles fronterizos, los acuerdos comerciales sectoriales que permiten la circulación de personas, las medidas de seguridad e información y los acuerdos sobre los derechos de los inmigrantes. Y la resultante Declaración de Rabat constató la necesidad de actuar de forma conjunta desde los países de origen, tránsito y destino de las migraciones con la convicción de que la gestión de las migraciones entre África y Europa debe inscribirse en el marco de la lucha contra la pobreza y la promoción del desarrollo sostenible, remarcando la necesidad de optimizar la gestión migratoria a partir de asumir la responsabilidad compartida en origen, transito y destino de las migraciones.

La agenda de este encuentro supondrá un claro protagonismo de la problemática específica de la cuenca del mediterráneo en el contexto más amplio de la Unión, con España a la cabeza de la formulación de propuestas, y el manejo de un discurso claramente positivo respecto a la migración, inscrita entre las prioridades del gobierno como parte de su lucha contra la pobreza. Como frontera Sur de Europa y frente a sucesos como la llegada de cayucos a las costas de Canarias desde Mauritania y Senegal y los incidentes de la valla de Melilla -que el Secretario de Estado de Seguridad Antonio Camacho calificó de -problema de Estado- (El País, 28/09/2005)-, España apuesta por reclamar la prioridad en la atención a su frontera como entrada irregular de flujos migratorios a Europa.

El Plan de acción que se acordó en Rabat implicaba el compromiso de la UE en la ayuda a los Estados africanos para construir su capacidad para gestionar la migración y el asilo, con el refuerzo de capacidades, en especial en la gestión aduanera, y el apoyo institucional con el fin de mejorar la acogida de migrantes y la protección de sus derechos. Así mismo, insiste en la búsqueda de un equilibrio entre la gestión de los flujos migratorios y el desarrollo, y de medidas que favorezcan el asentamiento de los emigrantes en los países de origen, tales como: la reducción de los costes del envío de remesas, el apoyo técnico para la generación de proyectos empresariales en origen, microcréditos, formación e intercambios universitarios que puedan evitar la fuga de cerebros, o planes de migración temporal que faciliten el regreso de los emigrantes.

Documentos posteriores de la Unión confirman el peso del vínculo migración y desarrollo en la política comunitaria. Véase por ejemplo, el texto de la Comisión: "Reforzar el planteamiento global de la migración: aumentar la coordinación, la coherencia y las sinergias» (2008), con un apartado dedicado a la Migración y Desarrollo. En él se recogen las numerosas iniciativas en curso en esta materia, como las concernientes a la gestión de las remesas, los retornos y a la fuga de cerebros, y se incorpora a los textos la importancia de dirigir actuaciones para favorecer la incorporación de las diásporas a las actuaciones de fomento del desarrollo en origen. En este sentido, el documento apoya las iniciativas de los grupos de emigrantes y las organizaciones de la diáspora para implicarse en las iniciativas 
políticas de la UE con y sobre sus países y regiones de origen, las iniciativas específicas en materia de agilización de los intercambios, fomento de la inversión y redes transnacionales de la diáspora, y la implicación de las diásporas en actividades de desarrollo en sus países de origen.

\section{LA APUESTA ESPAÑOLA POR EL NEXO MIGRACIÓN Y DESARROLLO EN EL MARCO DE LAS POLÍTICAS PÚBLICAS}

Hablar del nexo migración y desarrollo en España requiere tener presente las propuestas generadas en el marco europeo y retomar el término recogido en Tampere: el codesarrollo, un enfoque que se está discutiendo e implementando en Europa, que Francia lideró e incorporó como política pública a finales de los años 90, y en el que España está trabajando de manera más intensa en la actualidad.

Podemos señalar algunos rasgos que parecen identificar el enfoque: el codesarrollo plantea conectar de forma positiva las migraciones con el desarrollo; propone una relación nueva y paritaria, una colaboración mutua y consensuada, entre países de origen y destino de los flujos migratorios; sostiene la necesidad y la idoneidad de colocar a los migrantes en el centro de las acciones, como protagonistas de los procesos; y requiere de una acción coordinada de actores diversos, públicos y privados y de ambos lados del flujo, involucrados en acciones transnacionales de todo tipo (actividades productivas, formativas, de participación política, etc.) (Giménez et al., 2006). Estos principios generales así planteados, no influyen exclusivamente en la implementación de iniciativas pretendidamente novedosas en las formas de abordar proyectos. Tratan de trascender esas actuaciones más inmediatas y convertirse en un modelo de actuación eficaz, justo y coherente, en donde la vinculación entre las migraciones y el desarrollo contribuya a consolidar un modelo que establezca competencias compartidas en la gestión de las cuestiones globales, pautas diferentes en las relaciones bilaterales entre países emisores y receptores de flujos migratorios, visiones enriquecedoras e integrales sobre las migraciones y los migrantes, así como a afianzar prácticas alternativas en la cooperación para el desarrollo tradicional.

El codesarrollo se ha convertido en un término recurrente en los ámbitos y entre los actores que trabajan en la cooperación y la atención y gestión de las migraciones en España. Sin embargo, no pasa desapercibido el hecho de que en un planteamiento como éste, caben interpretaciones diversas. En este sentido, el trabajo de campo ${ }^{3}$ ha mostrado cómo, si atendemos a la forma en que se está dando el codesarrollo en la práctica en España, está siendo protagonizado, funda-

\footnotetext{
${ }^{3}$ En el marco de la tesis doctoral se han realizado entrevistas a miembros de administraciones públicas, de ONGD y asociaciones de migrantes implicados en actuaciones de codesarrollo, y se ha realizado así mismo observación participante en eventos, cursos y encuentros sobre esta temática entre 2004 y 2009.
} 
mentalmente, por tres actores: las administraciones públicas, las ONG y ONGD y las asociaciones de migrantes. Existen otros muchos que participan, como las iglesias, los sindicatos, los centros de investigación, o los bancos, pero el impulso y el protagonismo en los proyectos y las propuestas lo representa este modelo a tres (Sanmartín, 2009).

En dicha tríada, queremos focalizar la atención en las administraciones públicas, ya que los contenidos de los planes y las políticas que abordan el codesarrollo en los tres niveles administrativos (nacional, autonómico y municipal), resultan claves para entender los marcos normativos en los que se encuadran las actuaciones en proceso ejecutadas por todos ellos, y el posicionamiento político de España respecto al nexo migración y desarrollo. No hay que olvidar, tal y como señalan los análisis sobre política pública, que las administraciones tienen a su alcance todo tipo de recursos -recursos económicos, políticos, cognitivos y normativos- para poder influir, condicionar, bloquear o activar las decisiones públicas. Es decir, apoyadas en el argumento de que sus decisiones responden a intereses generales, pueden obligar a los demás desde su posición soberana y representativa. Por tanto, encarnan aquello que coyunturalmente se entiende como «intereses generales» (Subirats, 2001), paraguas bajo el que trabajan las organizaciones de la sociedad civil.

Una lectura detenida por los textos de dichos actores nos deja ver que existen matices comunes y diferenciales en el tratamiento y el enfoque que se da al codesarrollo. Diferencias que tienen que ver con factores políticos y coyunturales, que determinan los posicionamientos de cada administración y departamento -pues cada una responde a intereses plurales, son diversos los miembros que ocupan puestos en sus organismos, sus principios rectores, las repercusiones políticas y sociales de sus propuestas, el grado de responsabilidad y rendimiento de cuentas, o el territorio sobre el que gobiernan-, todo lo cual tendrá como resultado la existencia de discursos y de finalidades diversas en el diseño de actuaciones.

En cuanto a los elementos comunes, podemos destacar que, en general, los contenidos del codesarrollo en los ámbitos institucionales tienen que ver con una regulación restrictiva de los flujos en lo que se refiere a las entradas de migrantes en el país receptor. En este sentido, el fomento del desarrollo se ve como una alternativa a la migración. Las propuestas, sin embargo, se matizan con la idea de que utilizando a los migrantes como vectores de desarrollo se propiciará, en conjunto, el desarrollo de los países emisores de migrantes y, en consecuencia, disminuirá el flujo de entradas. Pero hay rasgos diferenciales en cada nivel territorial, siendo los elementos que tienen que ver con la integración, más relevantes en los programas municipales y autonómicos, pues el factor proximidad hace de estas administraciones ámbitos clave para trabajar con la inmigración en este campo.

Es importante subrayar que en España las competencias en materia de inmigración corresponden de forma exclusiva al Estado, junto con las cuestiones de la nacionalidad, la emigración, la extranjería y el derecho de asilo. Así aparece recogido en la Ley orgánica 4/000 y sus sucesivas reformas, sobre derechos y libertades 
de los extranjeros en España y su integración social (LODYLE). Sin embargo, en muchos aspectos relacionados con la acogida e integración de los inmigrantes no hay una única capacidad competencial, sino que comunidades autónomas y municipios comparten la titularidad con el Estado, que en este terreno centra su actuación en la creación de un fondo presupuestario para las mismas y en el diseño de un marco general que permita aunar criterios. Por tanto, el campo de la inmigración constituye un terreno de intervención que compete, en diferentes niveles, a todas ellas, y en donde se van a escenificar tensiones políticas por un ámbito en expansión, la inmigración, que permite incidir en terrenos estratégicos. En este sentido, por ejemplo, el codesarrollo abre una nueva posibilidad: el ir más allá de las labores de atención a los inmigrantes en sus territorios y ampliar la acción hacia el exterior, conectándose con los municipios y regiones de procedencia de los migrantes en acciones transnacionales de fomento del desarrollo.

Esta división competencial es una de las claves que pueden ayudarnos a entender el motivo por el que nuestro país parece haber tomado el relevo francés en Europa en la implementación de un enfoque como el codesarrollo. Pero antes de concretar qué elementos incorpora el codesarollo en el discurso y en la práctica española, es necesario atender al contexto específico y el posicionamiento español respecto a las formas de regulación de la cuestión migratoria a partir del 2001, año en que por primera vez aparece recogido el término en el Programa Global de Regulación y Coordinación de la Extranjería y la Inmigración (conocido como Programa GRECO).

\section{La construcción de la España inmigrante}

Podemos citar algunas cifras de referencia que muestran el porcentaje de población migrante en España para este periodo. Según los resultados de la explotación del Padrón Municipal a fecha 1 de enero de 2002, eran 1.977.944 los extranjeros empadronados en alguno de los municipios de España, lo que representaba un $4,73 \%$ de la población total empadronada. Con respecto al año anterior, que había 1.370.657, el aumento es del 44,31\%; es decir crece el número de extranjeros, aunque un poco menos que el año anterior que lo había hecho un $48,36 \%$, lo que supone un cierto freno teniendo en cuenta que la variación del año 2000 fue de 23,36\% y la de 1999 de 17,56\% (INE, 2004).

Las cifras, aunque en aumento progresivo, no muestran una aceleración notable. Pero a partir de año 2000 se habla de una «tercera etapa» en la constitución de «la España inmigrante». Esta fase tiene que ver con la ubicación de la migración como una cuestión política: «en torno a este año se produce la «institucionalización» de la inmigración en España como un «hecho social» o como un "problema social» (Cachón, 2003: 226). 
La gestión migratoria, en pleno debate europeo por consensuar medidas comunes para la Unión, se sitúa en el ámbito de la discusión pública y política en el contexto nacional. Desde la Cumbre de Tampere los esfuerzos parecen querer superar las políticas de control de flujos hacia el exterior, y ampliarse a la búsqueda de mecanismos con el interior que garanticen y faciliten la integración social de los inmigrantes en los países europeos. En España, las medidas adoptadas se van a mover en un modelo dual ente aquellas dirigidas al control y restricción de los flujos, competencia de la Administración Central, y las encaminadas a la inserción de los inmigrantes en la sociedad receptora, en manos de las administraciones autonómicas y municipales fundamentalmente.

Efectivamente, a partir del año 2000 se suceden en España un conjunto de acontecimientos que hacen de este momento, un periodo relevante. Se aprueban planes de integración para los inmigrantes en ocho diferentes comunidades autónomas, se discuten y suceden dos leyes de extranjería (4/2000 y 8/2000) y se convocan procesos extraordinarios de regularización (2000 y 2001). Y es así mismo en este periodo cuando los medios de comunicación hablan reiteradamente de las migraciones y dan cuenta de los «problemas» que están desencadenando, con un hecho especialmente impactante: junto a la llegada de pateras a las costa españolas, en febrero se producen ataques y disturbios en El Ejido (Almería) a raíz del asesinato de una joven (española) a manos de otro joven (marroquí). Un hecho que conmocionó a la opinión pública y provocó un intenso debate sobre el racismo y la tolerancia en España.

Las leyes de extranjería españolas operaron ese año una reestructuración administrativa relevante en cuanto al tratamiento de la inmigración. Se creó la figura del Delegado del Gobierno para los asuntos de Extranjería e Inmigración dentro del Ministerio del Interior. Un reflejo del peso que se otorga desde ese momento a la cuestión migratoria y un cambio de competencia que, así mismo, hacía explícita la prioridad concedida al criterio de control de la inmigración, de seguridad de las fronteras y de los intereses nacionales (Colectivo IOE, 2001). Y en este marco, en 2001 se pone en marcha el Programa GReCO, que identifica cuatro ámbitos clave de intervención:

1. Diseño global y coordinado de la inmigración como fenómeno deseable para España, en el marco de la Unión Europea.

2. Integración de los residentes extranjeros y sus familias, que contribuyen activamente al crecimiento de nuestro país.

3. Regulación de los flujos migratorios para garantizar la convivencia en la sociedad española.

4. Mantenimiento del sistema de protección para los refugiados y desplazados. 
El Plan recoge los principios acordados en Europa (la «perspectiva global de la inmigración») y los adecua, a su vez, a las particularidades del contexto español, en varios sentidos:

- en cuanto a su configuración territorial (reconoce explícitamente el papel fundamental de los gobiernos regionales y locales en la integración de la población inmigrante);

- su situación geográfica (es frontera sur-oeste de Europa y por tanto, puerta de entrada de la inmigración);

- a los rasgos particulares de la migración que recibe y a sus formas de instalación (lugares de origen, composición de los flujos, necesidades para la integración, etc.);

- a las necesidades internas del mercado de trabajo nacional. De hecho, se subraya el aporte positivo de la inmigración "como fenómeno deseable para España», por sus contribuciones activas al crecimiento del país, sus cotizaciones al sistema de la Seguridad Social y el pago de impuestos. Pero este aporte queda supeditado muy explícitamente a las necesidades unilaterales de España como país receptor: «[...] no podemos olvidar que España tiene ciudadanos propios sin empleo y dos millones de emigrantes, muchos de los cuales quieren volver a trabajar en su país; una capacidad de acogida limitada, que debe responder a un cálculo estricto de los puestos de trabajo que puede ofrecer a las personas extranjeras que emigran por razones económicas buscando entre nosotros oportunidades que no encuentran en sus propios países».

En este sentido, la ordenación de la llegada de inmigrantes al territorio es uno de los puntales del Programa, a partir de los cupos del contingente anual de trabajadores y de la firma de convenios sobre inmigración con los países emisores. Junto a esta protección de los intereses nacionales, a la preocupación por el control para impedir la «inmigración clandestina y la permanencia ilegal entre nosotros», y a la percepción «utilitarista» de la migración para España, también es cierto que el GRECO es la primera iniciativa que presenta acciones dirigidas a la lucha contra las redes de tráfico de personas y las que facilitan la inmigración irregular. Así mismo, al menos a un nivel declarativo, reconoce la necesidad de acordar «medidas de integración» con el conjunto de las administraciones públicas y con las organizaciones no gubernamentales, un paso fundamental para articular el sistema de integración social y laboral de los inmigrantes en el país.

Pero son numerosas las críticas que recibió este Plan. Entre otras, en cuanto a la terminología empleada (hablaba de «ilegales»), la imagen que maneja de los migrantes (sesgándola hacia el motivo laboral), o los intereses unilaterales que guían las propuestas (enfocadas hacia los migrantes trabajadores y temporales que necesita el país).

Desde entonces la política española en materia migratoria ha hecho de la lucha contra la inmigración irregular y las redes de tráfico de personas, sus objetivos prioritarios, muy condicionada por la posición geográfica del país como frontera 
exterior de Europa y por la dimensión y gravedad de las llegadas de inmigrantes desde África a sus costas (López Sala, 2009).

En el marco de la Unión Europea, el Gobierno español ha jugado así mismo un papel importante en la inclusión de estos asuntos en la agenda común. En este sentido, España ha favorecido iniciativas como las destinadas a exigir visado a los nacionales de Ecuador y Colombia (dos de los colectivos con mayor presencia en España y con índices de crecimiento notables) que quieran acceder a territorio comunitario. Y es reveladora, en esta misma línea, la postura española durante su presidencia de la UE en 2002, que incluía la elaboración de un programa de repatriaciones de inmigrantes en situación irregular y la ejecución de operaciones conjuntas en las fronteras exteriores de la UE (Terrón, 2004). Fue entonces también cuando España trató de sacar adelante una propuesta para vincular las migraciones con las iniciativas de cooperación con los países emisores: la utilización de la ayuda al desarrollo como instrumento para frenar la inmigración irregulary la aprobación de normas que permitan suspender los acuerdos de asociación con los países terceros que no cooperen en la lucha contra la inmigración ilegal. La propuesta fue frenada por otros Estados miembro, pero muestra el acercamiento a un tratamiento policial de la inmigración frente a posturas más amplias como las iniciadas en Tampere.

\section{La postura española en la actualidad}

Este planteamiento frente a lo migratorio ha ido matizándose desde entonces, y en el transcurso del último periodo es donde podemos ubicar la consolidación del codesarrollo, un buen reflejo de la nueva postura de España frente a la inmigración y frente a los retos internacionales y globales que afronta como potencia europea. A partir de 2004, con el triunfo en las elecciones del Partido Socialista, la política migratoria adquiere un nuevo enfoque:

Aun sin cambiar significativamente sus prioridades, que continuaban siendo la gestión de los flujos migratorios, la lucha contra la inmigración irregular, y las políticas de integración y acomodación de los inmigrantes en el territorio español, el nuevo Gobierno socialista apostó, en su primera legislatura, por fortalecer la dimensión exterior de esta política (Pinyol, 2009: 276).

El Consenso Europeo sobre Desarrollo del año 2005 estableció la erradicación de la pobreza como un objetivo central de la política de desarrollo de la UE, y España ha asumido este reto como objetivo prioritario de su propia política de cooperación. Tal y como se expresa en el último Plan Director de la Cooperación Española correspondiente al periodo 2009-2012: 
El reconocimiento fundamental de la pobreza como causa y efecto de la negación de los derechos fundamentales, recogidos en la Declaración Universal de Derechos Humanos, impone una obligación sobre el conjunto de la comunidad internacional. Adicionalmente, en un mundo interdependiente, la persistencia de la pobreza no es sólo un mal para quien la padece, sino también una fuente de problemas que a todos concierne. (Plan Director 2009-2012: 6).

Así, la erradicación de la pobreza se ha convertido en una línea fundamental de la política de cooperación española. Y en dicho marco, las principales actuaciones nacionales en materia de migración y desarrollo, se expresan de este modo:

España está llevando a cabo un intenso trabajo que abarca fundamentalmente cuatro ámbitos: la necesidad de abordar estrategias de desarrollo amplias, que incidan en las causas profundas de los flujos migratorios generando expectativas de vida digna en los países de origen; el diseño y puesta en marcha de políticas públicas migratorias, adecuadas y coordinadas, en los países de origen, tránsito y destino; el despliegue de acciones humanitarias ante situaciones de necesidad; el apoyo y puesta en marcha de programas y proyectos en las áreas de migración y desarrollo y codesarrollo, implicando por tanto a las diásporas en España (Ministerio de Asuntos Exteriores y de Cooperación, Febrero 2008).

Bajo estas premisas, España está apostando políticamente por medidas que recojan dicha interconexión. Se trata de una postura y un tipo de discurso que pretende incorporar, así mismo, una propuesta novedosa, eficaz, incluyente y dialogada para tratar su gestión en el marco más amplio de la Unión.

Somos testigos del gradual protagonismo español en el impulso político de medidas relacionadas con la inmigración y la cooperación con países terceros desde 2005. Lo hemos visto en la propuesta conjunta española, francesa y marroquí durante la Conferencia Ministerial Euroafricana sobre las Migraciones y el Desarrollo. Una Conferencia que aúna esta nueva apuesta española con la ya tradicional preocupación por el control de las fronteras exteriores:

Desde 2006 España se ha convertido en un actor influyente en la política europea de fronteras a través de su énfasis en las iniciativas dirigidas a la cooperación con países de origen y tránsito, y su insistencia en el control fronterizo como una «cuestión común». La vigilancia fronteriza y la externalización en la ejecución han sido los dos elementos que mayor desarrollo han experimentado en los últimos años (López Sala, 2009: 36).

Por tanto, se va fraguando una política migratoria que quiere contribuir a la lucha contra la pobreza, centrada especialmente en la búsqueda de soluciones para África y que, al mismo tiempo, trabaje para asegurar el control de la llegada 
de inmigración. Tal y como expuso la Secretaria de Estado de Inmigración Consuelo Rumí: «evitar la llegada de subsaharianos no sólo depende de la acción de España y Marruecos, sino de toda la Unión Europea y del Magreb, ya que Marruecos, además de país emisor, se ha convertido en país de tránsito, y la frontera sur de España es también Europa» (El País, 28/09/2005).

El concepto de codesarrollo y sus contenidos, en este panorama, vendrían a sumarse como posibles respuestas a las necesidades españolas, a esa búsqueda de mecanismos de intervención, proporcionando un nuevo lenguaje y un nuevo tratamiento de lo migratorio, e incorporando la opción de articular relaciones diferentes ente los lugares conectados por la migración. Así mismo, en su surgimiento y consolidación precisamente en España, confluyen varios factores que lo posibilitan y potencian. ¿̀Por qué España liderea actualmente la propuesta del codesarrollo?, żqué elementos permite incorporar en el discurso y la gestión que lo hacen pertinente en la actualidad? Procedemos a enumerar algunos rasgos que se muestran relevantes al respecto:

1. El codesarrollo incorpora un discurso positivo de la migración y busca transformar la relación con los países emisores, superando la preocupación unilateral y exclusiva por los temas de seguridad de los países receptores. Ahora se habla de partenariados, de reparto de responsabilidades y de acuerdos de colaboración, como nueva estrategia de gestión.

2. Permite introducir el vínculo migración y desarrollo en la política pública nacional a partir de medidas concretas y en todos sus niveles territoriales. Y esta cuestión es una de las claves del éxito del enfoque en nuestro país: permite una gestión descentralizada, un modelo de cooperación de carácter horizontal que otorga un papel relevante y estratégico a la gestión de las autonomías y los municipios. De hecho, han sido las comunidades autónomas y los municipios quienes han apostado de manera más evidente por el codesarrollo (con líneas de financiación para proyectos e investigación, departamentos específicos, personal), fomentando la implicación en el seno de la sociedad civil (ONGD y asociaciones de inmigrantes fundamentalmente) e impulsando la firma de convenios de cooperación directa entre municipios (municipios de origen y de destino de los migrantes). ${ }^{4}$

No es casual que las primeras propuestas en España surgieran de las administraciones regionales. Nos referimos a las «Primeras Jornadas de Inmigración y Cooperación: hacia el Codesarrollo», organizadas por el Departamento de Vivienda y Asuntos Sociales del Gobierno Vasco ya en diciembre de 2002, que reunieron a representantes de asociaciones, organizaciones de cooperación, universidades y gobierno de Euskadi para discutir el concepto de codesarrollo y acercar posturas

\footnotetext{
${ }^{4}$ El interés por el papel de las administraciones locales en la gestión de las migraciones y en la implementación de programas de codesarrollo, lo hemos trabajado las Universidades Complutense y Autónoma de Madrid y Flacso de Ecuador, en el proyecto de investigación: «Diagnóstico aplicado para la gobernanza local de una acción municipal de codesarrollo desde la ciudad de Madrid: la Casa de las Migraciones de Quito» (2009), en el marco de la Red Universitaria de Investigación sobre Cooperación para el Desarrollo del Ayuntamiento de Madrid.
} 
entre actores. Así mismo, es igualmente significativo el hecho de que fuese desde un grupo parlamentario catalán desde donde se planteó una proposición de ley para discutir en el congreso la posibilidad de hacer del codesarrollo, una política de cooperación nacional (Proposición de Ley 122/000018, abril de 2004).

La idoneidad del codesarrollo para las administraciones españolas provendría del doble espacio que posibilita y articula: encaja con las necesidades españolas de reparto de competencias en la atención de lo migratorio (los temas de integración de la población migrante como vecinos de un municipio o una región), y con el papel cada vez más activo de los ayuntamientos y las comunidades en las actividades de cooperación con regiones del Sur.

3. Aúna el interés por trabajar medidas en dos sentidos, que respondan a las necesidades hacia dentro y hacia fuera en la atención a la cuestión migratoria: el codesarrollo pone en marcha actuaciones dirigidas a la integración de la población migrante en España (participación, refuerzo de las asociaciones, etc.), y a la intervención en origen "para generar desarrollo». En este sentido, la idea que se maneja es que a más desarrollo y generación de oportunidades, menos migración hacia los países receptores. Por tanto, es presentada como una medida efectiva y necesaria para intervenir en la gestión de la migración, a la vez que se trabaja por el desarrollo de las regiones expulsoras.

4. Responde además a las necesidades y estrategias nacionales en una coyuntura determinada: España tiene ya una trayectoria como país receptor de inmigración y se ha igualado a otros países europeos en este terreno. Las cifras indican que en 2008 el 11,4\% de la población residente en España es extranjera, cifra que asciende a 5,3 millones de habitantes, con un incremento interanual del 16,6\%. Según datos de Eurostat, en 2008 tres cuartas partes del crecimiento de la población de la Unión Europea se estima que proceden de la inmigración y, en términos relativos, España tendría el cuarto flujo migratorio más alto de toda la UE, con un 10,2 por 1.000 habitantes (INE, 2009).

5. Así mismo, España ha logrado ocupar un lugar en Europa como una de las principales potencias y se presenta como un país próspero e innovador, con soluciones a problemas comunes y posible líder de determinadas campañas. La más destacada en el tema que nos ocupa, es su posicionamiento respecto a la lucha contra la pobreza y la relación con países terceros emisores de migrantes. Y en este terreno el codesarrollo es un mecanismo idóneo para ocupar el espacio público en el debate de propuestas y ganar legitimidad frente a sus socios europeos. Se trata de un enfoque con el que se quiere abordar la complejidad de la migración en la actualidad, que atienda a la población en el territorio y que reconozca los múltiples vínculos que existen entre las sociedades de origen y destino; y un enfoque capaz de impulsar procesos de desarrollo, así como de activar otros que contengan las salidas de más migración hacia Europa. Un enfoque, en definitiva, de carácter preventivo, más acorde con los discursos actuales frente a la migración y la relación con terceros países. 
Somos un país relativamente joven en cuanto a la recepción de inmigrantes, sobre todo en comparación con otros de nuestros vecinos europeos y, por tanto, nuestra migración es más reciente. Pese a ello, hemos asistido a un cambio importante respecto a décadas precedentes de emisión y recepción de migrantes y en un breve periodo de tiempo, que nos ha colocado ante la necesidad de adoptar medidas de gestión, siendo como somos, además, frontera Sur-Oeste de Europa. De entre ellas, hoy encontramos las propuestas del codesarrollo como acciones específicas a implementar y como enfoque o filosofía de trabajo respecto a los migrantes que recibimos y a nuestra relación con los países de los que parten. Y la apuesta se está presentando en este sentido como un modelo novedoso, solidario, positivo y propositito que España está impulsando en respuesta a las necesidades actuales de lucha contra la pobreza, solidaridad con los países del Sur, regulación justa de los flujos migratorios y puesta en marcha de iniciativas eficaces de inclusión de la población migrante residente en el país; temas, todos ellos, que ocupan un lugar central en las agendas de los gobiernos y que, como hemos ilustrado, España impulsa en los encuentros internacionales.

\section{CONCLUSIONES}

Hemos querido aproximarnos a las particularidades del nexo migración y desarrollo desde una perspectiva territorial y exponer los elementos que confluyen en el contexto específico español.

En este sentido, hemos expuesto el discurso institucional -gubernamental de España como país receptor de inmigración y potencia europea-. El discurso dominante, desde el poder, utiliza canales privilegiados para una difusión que excluye otras formas alternativas y se muestra así mismo como legítimo, pues se erige como una teoría objetiva y oficial que lo convierte en una retórica capaz de disuadir sobre la veracidad de su descripción e interpretación de la realidad. La elección de este abordaje responde al hecho de que, a partir de estos discursos, se construyen significados sobre los que se normativiza la práctica, se diseñan las políticas sociales, se organizan las modalidades de respuesta y se estructuran las políticas de acción social (Agrela, 2009).

Por otra parte, la literatura nos muestra de qué modo la gestión política de los gobiernos se revela fundamental a la hora de influir en el beneficio de los efectos de las migraciones en el desarrollo, pues no nos encontramos ante una relación automática (Abad, 2005). Así pues, żqué particularidades encontramos en España como contexto receptor de inmigración? ¿̇ué elementos del contexto influyen en el vínculo entre la migración y el desarrollo? ¿Qué tipo de instrumentos están activando las administraciones para intervenir en esta relación?

La política oficial española ha encontrado en la defensa del vínculo migración y desarrollo, y en la implantación del codesarrollo como medidas concretas a 
aplicar, un espacio de presencia y liderazgo en el debate internacional, así como un recurso útil que da respuesta a una política hacia dentro y hacia fuera, en la gestión de las migraciones. Un tipo de intervenciones que permiten además, articular la división competencial de sus diferentes niveles administrativos, con un reparto de tareas donde existen intereses estratégicos para los actores. La posibilidad de ocupar mayores competencias por parte de las administraciones municipales y autonómicas en el ámbito migratorio y de la cooperación, resulta fundamental en la implantación del codesarrollo desde España.

Así mismo, parece detectarse una tendencia hacia la evolución de los contenidos del codesarrollo, desde concepciones ligadas al control fronterizo y a la seguridad nacional de manera casi exclusiva (Plan GRECO), hacia nociones de carácter preventivo, que ponen el énfasis en el establecimiento de mecanismos de cooperación con terceros países para reducir las causas que empujan a los sujetos a emigrar. Se trata de limitar las causas de emigración con el objetivo de ofrecer oportunidades reales de vida en los países de origen (Pinyol, 2009). Sin embargo, en esta preocupación prioritaria es donde reside la gran distancia entre un tipo de objetivos de carácter global, acordados en ámbitos internacionales y en marcos más amplios de decisión -que buscan modificar la orientación general de la política migratoria y del desarrollo-, y otro tipo de objetivos específicos, aquellos que se centran en el contenido de una actuación pública concreta -en este caso la gestión migratoria sobre territorios nacionales, regionales y locales-.

El codesarrollo alude a la importancia de aprovechar y facilitar los múltiples canales que la migración posibilita, entre los lugares donde se producen. En este sentido, hemos aludido a la necesidad de implicar a las diásporas en los procesos a emprender y a determinadas intervenciones que aparecen recogidas en la documentación pública, tales como: el incentivo en el envío de remesas, la facilitación de los retornos o el impulso de actividades productivas en origen que generen oportunidades de empleo. Efectivamente, este tipo de actuaciones pueden contribuir a activar los nexos entre origen y destino, pero responderán a un interés unilateral de España si el objetivo último, la prioridad, continúa siendo fijar a la población en origen y contener los flujos migratorios.

El codesarrollo oficial de las administraciones muestra una clara apuesta nacional hacia su incorporación en los programas y en las prácticas de la cooperación y de la integración de inmigrantes; es la introducción de una serie de medidas (financiación, firma de acuerdos, líneas de investigación específicas) que potencian el impulso evidente de este enfoque para el caso español, y en unos términos que interesan a los poderes públicos españoles. Queda por ver en un modelo así planteado cuál es el papel, por ejemplo, de los gobiernos y las administraciones de los países de origen de los migrantes, cuál es su rol en el diseño y la ejecución de las propuestas de codesarrollo, cuál es su postura al respecto (si son proactivos, si son meros facilitadotes de las propuestas que llegan desde España, si están al margen de las acciones en marcha). Cuál es, en definitiva, el modo en el que se 
concreta y materializa el trabajo aquí y allá, el papel real que tienen los migrantes y sus asociaciones en las acciones, la forma en la que se busca asegurar el beneficio mutuo. ¿̇Estamos ante un modelo que, efectivamente, interesa a los países para gestionar y actuar en los ámbitos de la cooperación y las migraciones? ¿̇Son extensibles las propuestas del codesarrollo a otras realidades y escenarios más allá del contexto español?

Las potencialidades que puede encerrar el codesarrollo como meta y como método para abordar el trabajo en cooperación y gestión migratoria, están directamente relacionadas con la voluntad política para trabajar en este terreno. Estamos ante un planteamiento político que habla de una renovación de las prácticas de la cooperación y de la gestión de las migraciones, de la necesidad de establecer fórmulas de intervención consensuadas y coordinadas en el diseño de sus actuaciones. Por ello, el tipo de regulación que efectivamente se está realizando en esta dirección será clave para entender el sentido que se le está dando, la forma que está adoptando, los ámbitos de actuación prioritarios que se le asignan, o los agentes que se designa como encargados de ejecutar las acciones.

\section{BIBLIOGRAFÍA}

ABAD, Luis V. (2005), «Impacto de la emigración y las remesas en el desarrollo. Un enfoque desde las 'condiciones iniciales'», Revista Migraciones, Madrid, núm. 18: 105-148.

Agrela, Belén (2009), «De los significados de género e inmigración reproducidos en las políticas sociales y sus consecuencias para la acción e integración social», en Lorenzo Cachón, y Miguel Laparra (eds.), Inmigración y politicas sociales, Edicions Bellaterra, Barcelona.

Appleyard, Reginald (1992), «International Migration and Development: An Unresolved Relationship", International Migration Review, Nueva York, vol. xxx, núm. 3-4: 487499.

Asamblea General de Naciones Unidas (2006), Diálogo de Alto Nivel sobre la Migración Internacional y el Desarrollo, Nueva York, 14-15 de septiembre.

Boletín Oficial de las Cortes Generales, Congreso de los Diputados (2004), Proposición de Ley 122/000018, Vinculación de la política de cooperación internacional para el desarrollo con la política de inmigración, Presentada por el Grupo Parlamentario Catalán (Convergència i Unió), Madrid, Abril 2004.

CACHón, Lorenzo (2003), «La inmigración en España: los desafíos de la construcción de una nueva sociedad», Revista Migraciones, Madrid, núm. 14, diciembre, 219-304.

Colectivo Ió́ (2001), Política migratoria española en el marco europeo, $4^{\circ}$ Meeting internazionale di Loreto, Europa: Dialogo tra le culture, una sfida, 23-25 julio, Loreto, Italia.

Comisión Europea (2008), Comunicación 611 final: Reforzar el planteamiento global de la migración: aumentar la coordinación, la coherencia y las sinergias.

Conferencia Euroafricana sobre Migración y Desarrollo (2006), Declaración de Rabat. Consejo Europeo de Tampere (1999), Conclusiones de la Presidencia, 15-16 de octubre. 
Consejo Europeo de Bruselas (2005), Planteamiento global sobre migración: Acciones prioritarias en África y el Mediterráneo, diciembre.

Cortés, A. y A. SAnmartín (2009), "Las prácticas transnacionales de los/las migrantes vinculadas al desarrollo. Un estudio a partir del contexto español», Revista del Ministerio de Trabajo e Inmigración. Migraciones Internacionales, Madrid, núm. 80: 191-209.

Delgado Wise, R., H. Márquez y H. Rodríguez (2009), «Seis tesis para desmitificar el nexo entre migración y desarrollo», Revista Migración y Desarrollo, núm. 12, primer semestre. El país (2005), periódico consultado en 28/09/2005.

Escrivé, Ángeles y Natalia Ribas (coords.) (2004), Migración y desarrollo, csic, Córdoba.

García Zamora, Rodolfo (2005), Migración, remesas y desarrollo. Los retos de las organizaciones migrantes mexicanas en EE.UU., Colección Ángel Migrante, Méjico.

Giménez, C., J. Martínez, M. Fernández y A. Cortés (2006), El codesarrollo en España. Protagonistas, discursos y experiencias, Los libros de la Catarata, Madrid.

Hass de, H., O. Bakewell, S. Castles, G. Jonsson y S. Vezzoli (2009), Mobility and human development, Human Development Research Paper 2009/01, April.

INE (2004), Los extranjeros residentes en España. 1998-2002, Marzo. (2009), España en cifras, Mayo.

López Sala, Ana María (2009), El control de los flujos migratorios y la gestión política de las fronteras en España, en Ricard Zapata-Barrero (coord.) (2009), Políticas y gobernabilidad de la inmigración en España, Barcelona, Ariel.

Ministerio de Asuntos Exteriores y de Cooperación (2008), Principales líneas de actuación en Migración y Desarrollo, Febrero.

(2009), Plan Director de la Cooperación Española 2009-2012, Secretaría de Estado de Cooperación Internacional, Subdirección General de Planificación y Evaluación de Políticas de Desarrollo.

Ministerio del Interior de España (2001), Programa Global de Regulación y Coordinación de la Extranjería y la Inmigración (GRECO). Delegación del Gobierno para la Extranjería e Inmigración.

OIM (2003), Taller: Datos sobre la migración y el desarrollo, Diálogo internacional sobre las migraciones.

PinYol, Gemma (2009), La gestión de la acción exterior: iuna nueva diplomacia migratoria?, en Ricard Zapata-Barrero (coord.) (2009), Politicas y gobernabilidad de la inmigración en España, Barcelona, Ariel.

PNUD (2009), Informe sobre Desarrollo Humano 2009. Superando barreras: movilidad y desarrollo humanos.

Portes, A., C. Escobary A. Walton (2006), "Organizaciones transnacionales de inmigrantes y desarrollo: un estudio comparativo», Migración y Desarrollo, primer trimestre, 3-44. Sanmartín, Anna (2009), "Los actores del codesarrollo: el caso español», en A. Cortés y A. Torres (coords.) (2009), Codesarrollo en los Andes: contextos y actores para una acción transnacional, Quito, Flacso-Ecuador, Imedes-Uam y Cooperación Ciudad de Madrid.

Subirats, Joan (2001), El análisis de las políticas públicas, Gac Sanit 2001; 15 (3): 259-264. Terrón, Anna (2004), Migraciones y relaciones con países terceros, Serie Migraciones núm. 2, Barcelona, CIDOB, julio. 